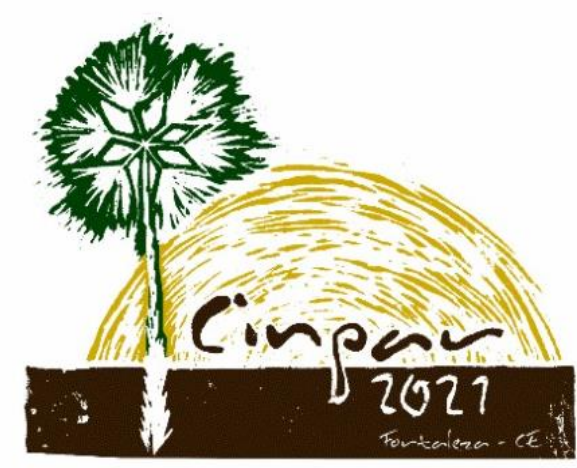

XVII Congresso Internacional sobre Patologia e Reabilitação das Construções

XVII Congreso Internacional sobre Patología y Rehabilitación de las Construcciones

XVII International Conference on Pathology and Constructions Rehabilitation

FORTALEZA (Brasil), 3 a 5 de junho de 2021 https://doi.org/10.4322/CINPAR.2021.047

\title{
Revisão bibliográfica- Estudo da mitigação de cristalização de sais em fachadas de revestimentos argamassados
}

\section{Bibliographic review - Study of the mitigation of crystallization of salts in facades with mortar coatings}

\author{
Elton BAUER ${ }^{1}$, Ana LOPES ${ }^{2}$ \\ ${ }^{1}$ Universidade de Brasília, Brasília, Brasil, e-mail: elbauerlem@gmail.com \\ 2 Universidade de Brasília, Brasília, Brasil, e-mail: anacclopess@gmail.com
}

\begin{abstract}
Resumo: $O$ surgimento das marcas de deterioração nas fachadas dos edifícios é resultado dos agentes externos, como por exemplo: umidade, temperatura, vento, entre outros. Patologias como: eflorescência, fissuras e até desplacamentos são exemplos desse desgaste, que pode ser ocasionado por deficiência em projetos ou até mau uso. Tais manifestações patológicas, podem ser minimizadas com a escolha correta de matérias (aditivos e teor de aglomerante) e parâmetros de dosagem como: a consistência das misturas e teor de ar incorporado. A degradação por cristalização de sais, como causa da deterioração, em materiais porosos como a argamassa, é um problema provocado principalmente pela presença de sais solúveis e umidade. Esta, pode gerar falhas na estrutura porosa do material, de forma macroscópica ou até microscópica. Neste sentindo, o estudo em questão avaliou de que forma a estrutura porosa das argamassas influenciam na cristalização dos sais. Assim como, fatores que irão determinar a estrutura porosa da mesma, como: os aditivos modificadores de cristalização (bórax e ferrocianeto), silicones e polímeros, teor de aglomerante, consistência e teor de ar incorporado. Através de estudos já realizados, foram correlacionados aspectos como capilaridade, porosidade e resistências mecânicas. Como resultados dessa investigação, contribuir para o entendimento do fenômeno de cristalização de sais em argamassas de revestimento.
\end{abstract}

Palavras-chave: Cristalização de sais, Reabilitação, Patologia, Degradação, Argamassa.

Abstract: The appearance of deterioration marks on the facades of buildings is the result of external agents, such as: humidity, temperature, wind, among others. Pathologies such as: efflorescence, cracks and even leaks are examples of this wear and tear, which can be caused by deficiency in projects or even misuse. Such pathological manifestations can be minimized with the correct choice of materials (additives and binder content) and dosage parameters such as: the consistency of the mixtures and the content of incorporated air. Degradation by crystallization of salts, as a cause of deterioration, in porous materials such as mortar, is a problem caused mainly by the presence of soluble salts and moisture. This can cause flaws in the porous structure of the material, either macroscopically or even microscopically. In this sense, the study in question evaluated how the porous structure of mortar influences the crystallization of salts. As well as, factors that will determine its porous structure, such as: crystallization modifying additives (borax and ferrocyanide), silicones and polymers, agglomerate content, consistency and incorporated air content. Through studies already carried out, aspects such as capillarity, porosity and mechanical resistance were correlated. As a result of this investigation, contribute to the understanding of the phenomenon of crystallization of salts in coating mortars.

Keywords: Salt crystallization, Rehabilitation, Pathology, Degradation, Mortar. 


\section{Introdução}

Os revestimentos exteriores de paredes desempenham um papel fundamental na proteção dos edifícios contra os agentes de degradação. Assumem grande importância na conservação das construções, especialmente na proteção contra ações climáticas, choques mecânicos e contaminação ambiental afetando de um modo geral o conforto, a salubridade, o aspecto estético e a durabilidade das edificações (QUINTELA, 2006). Por tanto, devem ser cumpridas funções de proteção e impermeabilização das fachadas durante a vida útil do edifício, com a finalidade de contribuir para a estanqueidade do sistema de revestimento.

Antes mesmo do final da obra e início da ocupação do edifício, a fachada, sujeita aos agentes atuantes, inicia seu processo de degradação. Este desgaste natural no decorrer dos anos, proporciona o surgimento de manifestações patologias, como, fissuração, desplacamento, manchas, dentre outras, que catalisam este processo de degradação. Deste modo, identificar essas patologias, apontar suas origens, entender causas e discernir suas tipologias, pode possibilitar ações preventivas ainda na etapa de projeto e execução da obra. O conhecimento das manifestações patológicas contribui para a melhoria contínua dos processos construtivos, na medida em que as informações sobre as mesmas são tratadas e divulgadas (SANTOS, 2018).

A responsável por grande parte das anomalias construtivas é a água, sendo a principal causa da deterioração dos materiais de construção porosos, como a argamassa. Os problemas resultantes da presença da água, podem ser especialmente graves, nas construções antigas ou em materiais com maior sensibilidade a este agente (FREITAS, 1992). A cristalização de sais solúveis, ocorre com a presença de água e é uma causa comum de deterioração severa dos materiais de construção. Os danos ocorrem devido a ciclos repetidos de dissolução e recristalização dos sais solúveis dentro dos poros dos materiais de construção. Quando um cristal em crescimento fica confinado, ele irá exercer uma pressão na parede do poro, o dano ocorre se a pressão de cristalização se tornar maior do que a resistência do material.

A adição de modificadores de cristalização nas argamassas durante a mistura pode conferir-lhes uma resistência melhorada a degradação do sal. Modificadores de cristalização são íons ou moléculas que podem prevenir a nucleação (inibidores), promover a nucleação de uma determinada fase do cristal (promotores) e / ou modificar a forma dos cristais (modificadores de forma). Dessa forma, o sal pode ser transportado mais facilmente para a superfície do material, onde se cristaliza como eflorescência inofensiva (GRANNEMAN, 2019).

Com isso, o objetivo desse trabalho é analisar aspectos como a porosidade, capilaridade e resistências mecânicas de trabalhos já desenvolvidos, e assim correlacionar os resultados com intuito de avaliar como estes aspectos influenciam por exemplo, na velocidade de secagem, na taxa de absorção por capilaridade e também o desempenho mecânico de cada argamassa, associando assim ao fenômeno de cristalização de sais.

\section{Metodologia}

Utilizou-se trabalhos já desenvolvidos do Programa de Pós-graduação em Estruturas e Construção Civil da Universidade de Brasília. Foram analisados com a finalidade de correlacionar aspectos que possam influenciar na estrutura porosa das argamassas, como porosidade, capilaridade, secagem e resistências mecânicas e secagem. Para que assim possa se determinar como isto poderá atuar na mitigação de cristalização de sais nessas estruturas.

A investigação foi realizada em resultados de 5 trabalhos, sendo que um deles tem um conjunto de 6 traços de argamassas e os demais tem um conjunto de 3 traços cada. As argamassas foram produzidas com traços diferentes, no entanto o trabalho 1 e 2 foram produzidas com mesmo traço, no primeiro realizou-se uma parte da análise das argamassas no estado fresco e no segundo foi realizado o estado endurecido. nomenclaturas das argamassas estão de acordo com cada traço correspondente. Abaixo está descrita cada nomenclatura com suas respectivas descrições.

A variabilidade dos traços ajudou a prever o comportamento em relação a estrutura porosa da argamassa, e como essa estrutura se comportará frente a umidade, de acordo com as quantidades de água, aglomerante, agregados e teor de ar incorporado. A umidade é um caso recorrente nos edifícios, pode-se dizer que é um 
dos principais responsáveis pela deterioração de matérias como blocos cerâmicos e argamassas, por exemplo, algumas técnicas já foram estudadas como tentativa de minimizar este problema. Com objetivo de mitigar o problema da umidade, são estudados alguns tipos de aditivos hidrofugantes, modificadores de cristalização e parâmetros de dosagem na tentativa de modificar a estrutura porosa das argamassas e influenciar no transporte de umidade. No quadro 1 estão enumerados os trabalhos com seus respectivos títulos e ano de publicação, de maneira crescente de acordo com o primeiro trabalho publicado.

Quadro 1 - Enumeração dos trabalhos com seus títulos, autores e ano de publicação.

\begin{tabular}{|c|c|c|}
\hline Trabalho & Título do trabalho & Autor /Ano \\
\hline 1 & $\begin{array}{l}\text { Avaliação do transporte de água em revestimentos de argamassa } \\
\text { nos momentos iniciais pós aplicação }\end{array}$ & Paes, 2003 \\
\hline 2 & $\begin{array}{l}\text { Contribuição ao estudo das propriedades físico-mecânicas das } \\
\text { argamassas de revestimento }\end{array}$ & $\begin{array}{l}\text { Araújo Jr, } \\
2004\end{array}$ \\
\hline 3 & $\begin{array}{c}\text { Contribuição ao estudo da fissuração, da retração e do mecanismo } \\
\text { de descolamento do revestimento á base de argamassa }\end{array}$ & $\begin{array}{l}\text { Pereira, } \\
2007\end{array}$ \\
\hline 4 & $\begin{array}{l}\text { Estudo da estrutura das argamassas de revestimento e sua } \\
\text { influência nas propriedades de transporte de água }\end{array}$ & $\begin{array}{l}\text { Salomão, } \\
2016\end{array}$ \\
\hline 5 & $\begin{array}{l}\text { Estudo comportamental da formulação, dos requisitos e das } \\
\text { propriedades das argamassas estabilizadas de revestimento }\end{array}$ & $\begin{array}{l}\text { Oliveira, } \\
2017\end{array}$ \\
\hline
\end{tabular}

As caracterizações de cada material estão descritas nos trabalhos citados no quadro 1, é importante lembrar que os grupos de argamassas foram produzidas com matérias diferentes. Foi selecionado somente os resultados dos ensaios de absorção de água por capilaridade, absorção de água por imersão, porosimetria e resistência a compressão e tração por flexão.

No quadro 2 está descrito a nomenclatura das argamassas com o respectivo tipo de agregado e parâmetro $\mathrm{E}$ (constante calculada a partir da relação água mais agregado e aglomerantes, com base nos estudos).

Quadro 2 - Nomenclatura das argamassas separadas por grupos.

\begin{tabular}{|c|c|c|}
\hline Trabalho & Nomenclatura & Descrição \\
\hline \multirow{3}{*}{1 e 2} & Arg. A / AR-2 & Argamassa com agregado miúdo tipo $A$, parâmetro $E=10$ \\
\hline & Arg. B/ AR-3 & Argamassa com agregado miúdo tipo $B$, parâmetro $E=10$ \\
\hline & Arg. C/ AR 4 & Argamassa com agregado miúdo tipo $C$, parâmetro $E=10$ \\
\hline \multirow{3}{*}{3} & E6 & Argamassa com parâmetro $\mathrm{E}=6$ \\
\hline & $\mathrm{E} 6 \mathrm{H}$ & Argamassa com parâmetro $\mathrm{E}=6$ \\
\hline & E12 & Argamassa com parâmetro $\mathrm{E}=12$ \\
\hline \multirow{6}{*}{4} & A1E6 & Argamassa com agregado miúdo tipo 1 (fino), parâmetro $E=6$ \\
\hline & A1E9 & Argamassa com agregado miúdo tipo 1 (fino), parâmetro $E=9$ \\
\hline & A1E12 & Argamassa com agregado miúdo tipo 1 (fino), parâmetro $E=12$ \\
\hline & A2E6 & Argamassa com agregado miúdo tipo 2, parâmetro $\mathrm{E}=6$ \\
\hline & A2E9 & Argamassa com agregado miúdo tipo 2, parâmetro $E=9$ \\
\hline & A2E12 & Argamassa com agregado miúdo tipo 2 , parâmetro $E=12$ \\
\hline \multirow{3}{*}{5} & $\mathrm{E} 4,5 \mathrm{~S} . \mathrm{A}$ & Argamassa com parâmetro $E=4,5$ \\
\hline & E6 S. A & Argamassa com parâmetro $\mathrm{E}=6$ \\
\hline & E8 S. A & Argamassa com parâmetro $\mathrm{E}=8$ \\
\hline
\end{tabular}


Os traços estão descritos no quadro 3, como a quantidade em massa de cada material e a relação água/ cimento de cada grupo de argamassas.

Em cada grupo há composições de argamassas diferentes, com agregados diferentes e também com quantidades de aglomerantes e água diferente, por tanto o conjunto de argamassas de um grupo é composta por argamassas diferentes entre si e diferentes também em relação aos outros grupos analisados.

Quadro 3 - Traços das argamassas separadas por grupos

\begin{tabular}{|c|c|c|c|}
\hline Grupos/trabalhos & Argamassas & Traços & a/c \\
\hline \multirow{4}{*}{1 e 2} & Arg. A/ AR-2 & $1: 0,73: 9,27: 1,97$ & 1,97 \\
\cline { 2 - 4 } & Arg. B/ AR- 3 & $1: 0,87: 9,13: 2,14$ & 2,14 \\
\cline { 2 - 4 } & Arg. C/ AR-4 & $1: 1,06: 8,97: 1,94$ & 1,94 \\
\hline \multirow{4}{*}{3} & E6 & $1: 0,24: 5,74: 1,32$ & 1,32 \\
\cline { 2 - 4 } & E6H & $1: 0,24: 5,74: 1,76$ & 1,76 \\
\cline { 2 - 4 } & E12 & $1: 1,01: 10,98: 2,52$ & 2,52 \\
\hline \multirow{4}{*}{4} & A1E6 & $1: 0,17: 6: 1,22$ & 1,22 \\
\cline { 2 - 4 } & A1E9 & $1: 0,37: 9: 1,79$ & 1,79 \\
\cline { 2 - 4 } & A1E12 & $1: 0,66: 12: 2,41$ & 2,41 \\
\cline { 2 - 4 } & A2E6 & $1: 0,07: 6: 1,17$ & 1,17 \\
\cline { 2 - 4 } & A2E9 & $1: 0,22: 9: 1,86$ & 1,86 \\
\cline { 2 - 4 } & A2E12 & $1: 0,45: 12: 2,54$ & 1,34 \\
\hline \multirow{4}{*}{5} & E4,5 S.A & $1: 4,5: 1,02$ & 1,87 \\
\cline { 2 - 4 } & E6 S.A & $1: 6,0: 1,36$ & 1,02 \\
\hline & E8 S.A & $1: 8,0: 1,87$ & 2,36 \\
\hline
\end{tabular}

\section{Resultados}

A partir dos resultados coletados nos 5 trabalhos estudados, foi possível construir gráficos com intuito de correlacionar as respostas dos ensaios, nos trabalhos 3 e 5 não foi realizado o ensaio porosimetria, por tanto haverá um espaço na linha que representa este ensaio nos gráficos seguintes.

3.1 Resultados da correlação do coeficiente de capilaridade, absorção por imersão e porosidade

A porosidade tem um papel importante no transporte de umidade nas argamassas e é relacionada com geometria dos poros. A noção da geometria dos poros está associada essencialmente ao tamanho e a forma dos poros, bem como da sua organização espacial. A relação água/cimento, quantidade de cimento, aditivos incorporadores de ar, aditivos hidorrepelentes entre outros determina como será a distribuição desses poros, e se eles serão conectados ou não (porosidade aberta ou fechada).

A capilaridade é uma das propriedades responsáveis pela água absorvida pelos revestimentos argamassados, sob a ação, por exemplo, de água das chuvas ou umidades ascensional dos solos na base dos revestimentos. Este fenômeno refere-se à movimentação de água pelos capilares dos revestimentos argamassados, sem pressão hidrostática significativa. (FILHO, 2013).

A figura 1 apresenta o gráfico com os resultados de coeficiente de capilaridade, absorção por imersão e porosidade, das argamassas dos 5 grupos analisados. É possível notar que há uma coerência nos resultados, 
pois a porosidade vai diminuindo de acordo com a diminuição do coeficiente de capilaridade e a absorção, o comportamento é linear e proporcional ao traço correspondente.

O menor volume de poros pode ser considerado um obstáculo ao transporte de água. De maneira análoga, supõe-se que a elevada densidade dos produtos de hidratação dos aglomerantes, em especial o cimento, diminui a dimensão dos poros na matriz cimentícia. Ou seja, quanto maior o teor de aglomerantes, mais finos são os poros.

A degradação pelo ataque de sais é inicialmente causada pela cristalização de sais nos poros devido ao aumento da pressão capilar e a evaporação ou ciclos de umedecimento e secagem. Quanto mais propicio for a absorção de água e mais rapidamente ocorrer a secagem pode haver a formação desses cristais de sais nos poros e afetar as argamassas.

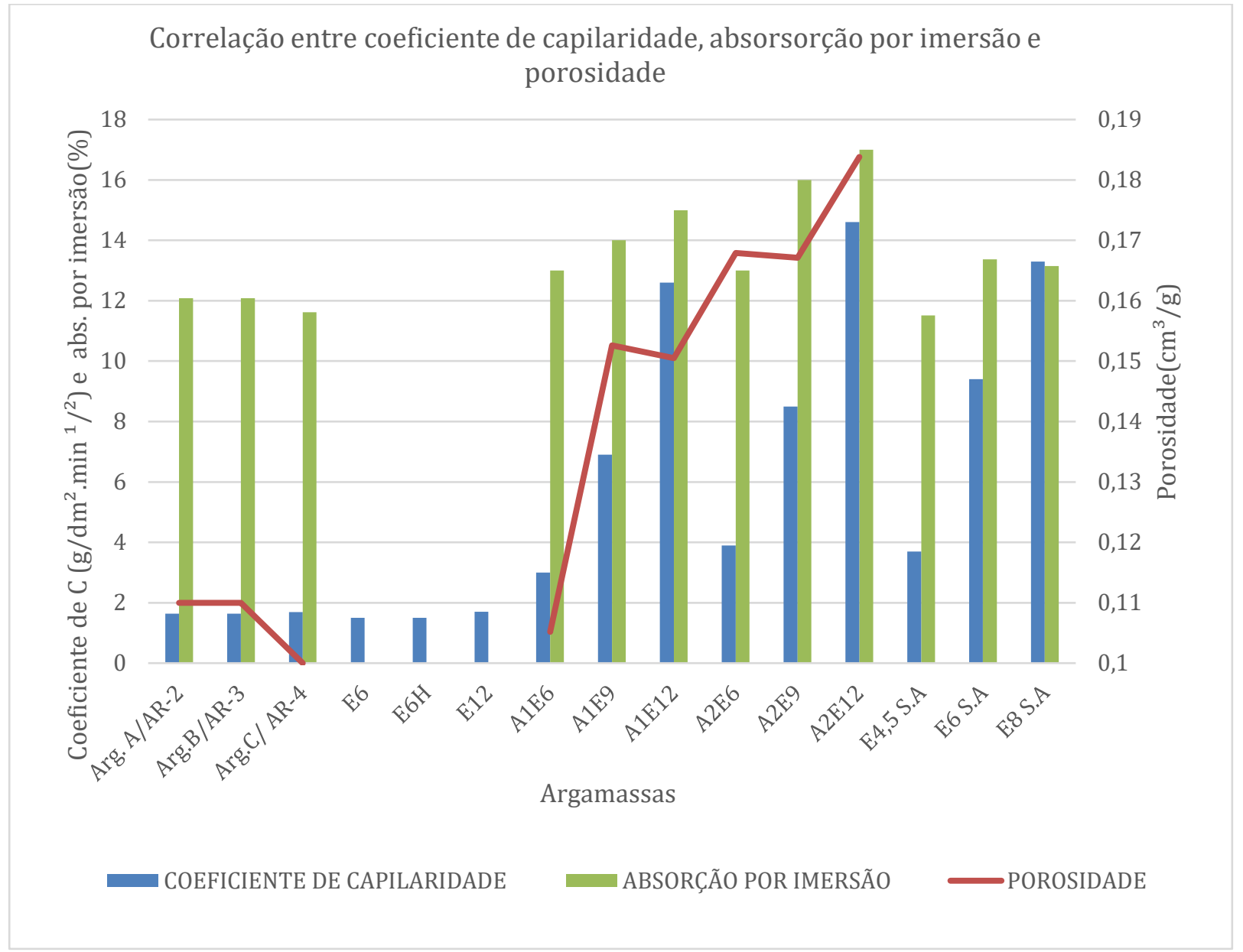

Figura 1 - Gráfico da correlação dos ensaios de capilaridade, absorção por imersão e porosimetria

\subsection{Resultados da correlação entre a resistências mecânicas e porosidade}

No resultado do ensaio de resistência à compressão foi possível notar que o teor de água e relação água/ cimento influenciaram nos resultados. Misturas com maior teor de água, maiores relações água/cimento e maior teor de ar incorporado apresentaram menores resistências. O comportamento do ensaio de resistência a tração por flexão apresentou as mesmas características. Como apresentado na figura 1, os resultados dos ensaios de resistência a compressão e resistência à tração por flexão respectivamente. É possível observar também uma relação dos resultados de resistência mecânica com a porosidade, pois à medida que a porosidade aumenta as resistências mecânicas aumentam, assim é possível notar que a porosidade influência nas propriedades mecânicas. 


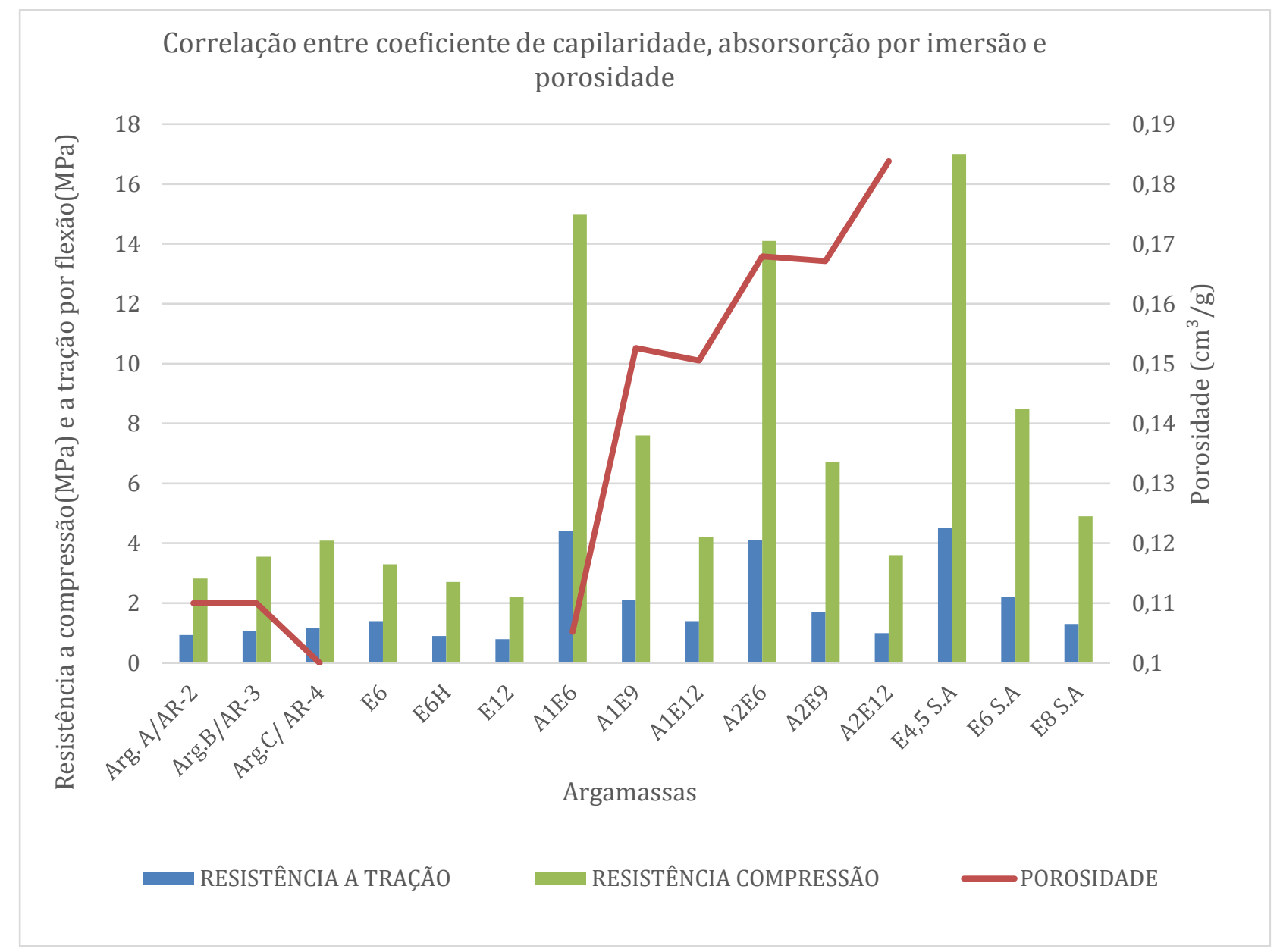

Figura 2- Gráfico da correlação dos ensaios de resistência a compressão e a tração por flexão e porosimetria

3.3 Ensaio de secagem e absorção por imersão nas argamassas do grupo 5

\begin{tabular}{|c|c|}
\multicolumn{2}{l}{ Quadro 4 - Ensaio de absorção por imersão } \\
\hline Trabalho & Absorção por imersão (\%) \\
\hline A1E6 & 13 \\
\hline A1E9 & 14 \\
\hline A1E12 & 15 \\
\hline A2E6 & 13 \\
\hline A2E9 & 16 \\
\hline A2E12 & 17 \\
\hline
\end{tabular}

Ao se observar o valor inicial das curvas de secagem das argamassas na figura 3, percebe-se que eles são muito semelhantes ao conteúdo de umidade mássico (teor de água) obtido por imersão como mostrado no quadro 4 foi semelhante para as argamassas. Isso indica que a condição inicial de ensaio reproduz o comportamento da argamassa na molhagem. 


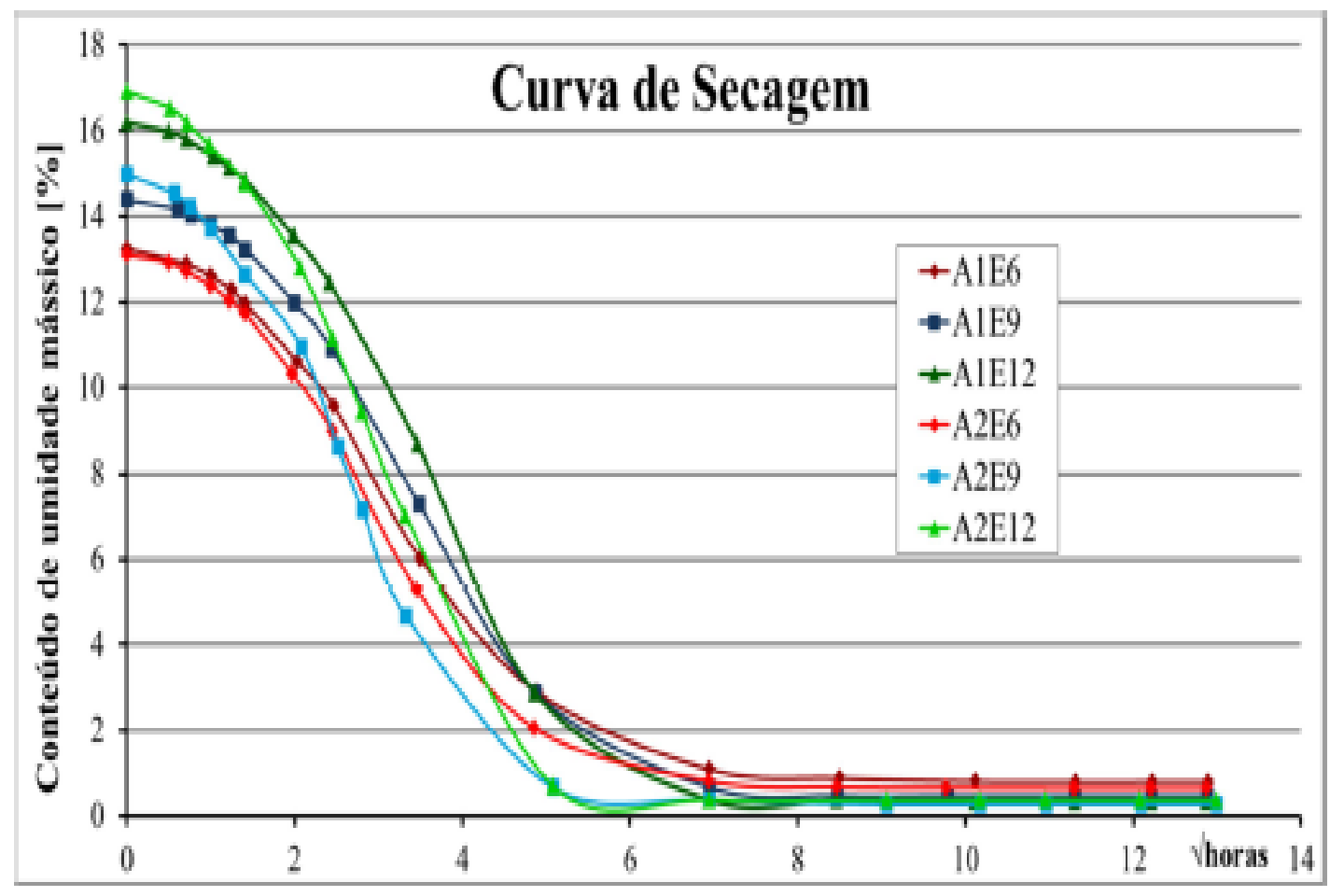

Figura 3 - Gráfico das curvas de secagem (adaptada de Salomão,2016)

Graficamente na figura 3 se torna mais clara a observação da diferença de secagem entre as argamassas E6, E9 e E12. As argamassas E9 e E12 começam o ensaio com conteúdo de umidade mássico mais elevado que as argamassas E6. No entanto, ao longo do ensaio as argamassas do grupo E6 perdem água mais lentamente. Ao final da secagem o conteúdo de água remanescente é mais alto para essas argamassas.

Já nas argamassas dos grupos E9 e E12, foi possível observar que além do teor de aglomerante o agregado utilizado foi determinante na secagem. As argamassas com agregado A1 secaram mais lentamente que aquelas com agregado $A 2$ (neste caso o agregado $A 1$ e $A 2$ foram considerados bem graduados e uniformidade média, no entanto A2 é mais fino que A1). (SALOMÃO,2016)

\section{Conclusão}

Com o estudo foi possível analisar que características como velocidade de secagem, capilaridade e porosidade influenciam diretamente na cristalização de sais solúveis nos poros das argamassas. Assim quanto maior a velocidade de secagem, a porosidade e a capilaridade maior serão a possibilidade de ocorrer a degradação por sais solúveis.

A capacidade de secagem é uma das características essenciais para avaliar o desempenho de uma argamassa face à água. Como se sabe, a água é um dos principais agentes de degradação dos rebocos. Deste modo, quando ocorre a sua entrada, o reboco deve possibilitar a sua saída assim que as condições atmosféricas o permitam (VEIGA, 1998). Os sais solúveis estão presentes nos materiais de construção sob a forma de soluções aquosas que migram na rede porosa. Admite-se que, em geral, a sua cristalização decorre de processos evaporativos, embora as variações de temperatura possam também ter influência para alguns tipos de sais.

Já em relação as propriedades mecânicas foram possíveis constatar que quanto maior for a porosidade menor será as resistências mecânicas, no entanto se faz necessário um estudo mais aprofundado para analisar todos os parâmetros envolvidos que neste trabalho não foram estudados, como o teor de ar incorporado, granulometria dos agregados entre outros. 


\section{Referências Bibliográficas}

ARAÚJO Jr, J. M. Contribuição ao estudo das propriedades físico-mecânicas das argamassas de revestimento. Dissertação de mestrado, Universidade de Brasília, 2004.

FREITAS, V. Transferência de humidade em paredes de edifícios. Análise do fenómeno da interface. Tese de doutoramento, Faculdade de Engenharia da Universidade do Porto, Porto. 1992.

GRANNEMAN, S. J. C.; LUBELLI, B.; HEES, R. P. J. VAN. Characterization of lime mortar additivated with crystallization modifiers. International Journal of Architectural Heritage, v. 12, n. 5, p. 849-858, 2018.

OLIVEIRA, V.C. Estudo comportamental da formulação, dos requisitos, e das propriedades das argamassas estabilizadas de revestimento. Dissertação de mestrado em Engenharia civil, Universidade de Brasília. 2017

PEREIRA, C. H. A. F. Contribuição ao estudo da fissuração, da retração e do mecanismo de descolamento do revestimento à base de argamassa. Tese de doutorado, Universidade de Brasília, 2007.

QUINTELA, M. Durabilidade de revestimentos exteriores de parede em reboco monocamada. Dissertação de mestrado em Engenharia Civil, Faculdade de Engenharia da Universidade do Porto, Porto. 2006.

SANTOS, D.G. Estudo da vida útil e degradação de fachadas em argamassas a partir da inspeção de edifícios. Dissertação de mestrado, Universidade de Brasília, 2018.

SALOMÃO, M.C.F. Estudo da estrutura das argamassas de revestimento e sua influência nas propriedades de transporte de água. Tese de doutorado, Universidade de Brasília, 2016.

SELMO, S.M.S. Dosagem de Argamassas de Cimento Portland e Cal para Revestimento Externo dos Edifícios. Dissertação de Mestrado, Escola Politécnica da Universidade de São Paulo, 1989.

VEIGA, M. R. Comportamento de argamassas de revestimento de paredes, contribuição para o estudo da sua resistência à fendilhação, Dissertação de Doutoramento em Engenharia Civil, FEUP, Porto. 1998. 